\title{
Analysis of Heat Loss of a Biogas Anaerobic Digester in Weather Conditions in Poland
}

\author{
Tomasz Janusz Teleszewski ${ }^{*}$, Mirosław Żukowski ${ }^{1}$ \\ 1 Department of HVAC Engineering, Faculty of Civil and Environmental Engineering, Bialystok University of \\ Technology, Wiejska 45E, 15-351 Bialystok, Poland \\ * Corresponding author's e-mail: t.teleszewski@pb.edu.pl
}

\begin{abstract}
Currently in Poland, the construction of biogas plants as alternative energy sources is increasing. Often, the technical solutions for design and building of biogas plants are transferred to Poland from the countries in which these technologies are developed without taking into account the specific climatic conditions prevailing in Poland. It does occur that newly built biogas plants have a problem maintaining a sufficiently high temperature in the winter, which is caused by the insufficient insulation of the biogas anaerobic digester envelope. This paper presents an analysis of heat loss, depending on the climatic conditions prevailing in Poland and the working conditions of a biogas plant, based on an existing facility located in Ryboly (Poland). The work is supplemented with the results of tests using a thermal imaging camera. It should be noted that currently there are no requirements in the literature regarding the design of a thermal insulating layer in biogas installations in Poland.
\end{abstract}

Keywords: biogas anaerobic digester, heat demand, heat losses

\section{INTRODUCTION}

Biogas plants are one of the most extensively developing and promising renewable energy sources in Poland. This green technology can also limit the environmental nuisance resulting from agricultural activities (Białowiec et al. 2015, Sadecka 2016) and wastewater treatment (Lebiocka 2010, Kogut et al. 2012, Montusiewicz 2014, Pilarska 2018). The use of the waste as a substrate makes a biogas plant a pro-ecological alternative energy source that contributes to the improvement of the quality of the environment, and this technology can be considered as an integral part of the environmental protection.

Biogas plants can also reduce the environmental nuisance resulting from the agricultural activities. The main advantages of this technical solution include:

- The use of farmyard manure, farm slurry, agricultural and municipal waste, sewage, crops, and many kinds of plant materials as a fuel.
- Heat and electricity cogeneration with high efficiency.

- Improvement of the sanitary conditions of the environment.

- Increase of the energy security at the local level by reducing the consumption of fossil fuels.

- Independence of energy production from the atmospheric conditions and seasons.

- Reduction of the greenhouse gas emissions.

- Aid in recycling of phosphorus and nitrogen.

- Reduction of unemployment in rural areas.

The biogas plants also have certain disadvantages:

- Relatively high investment costs (a mediumsized biogas plant costs about 3 million euros).

- Introduction of monocultures in crops.

- Competition for food production.

- Common problems with finding customers for the generated heat energy.

- Lack of clear regulation and a large bureaucracy in Poland. 
According to the Polish Energy Policy until 2030, an average of one biogas plant in each municipality will be constructed by 2020 . Therefore, the issues related to the production of biogas will become increasingly widespread. These types of energy sources operate in two temperature ranges: $25-37^{\circ} \mathrm{C}$ (mesophilic fermentation) and $45-55^{\circ} \mathrm{C}$ (thermophilic fermentation). In both cases, the temperature inside the bioreactor chamber (anaerobic digester) is above the ambient temperature. Thus, there is always a heat loss to the outside environment.

The thermal performance of the tubular digester located on the Agronomy Campus in Cusco (Peru) was developed by Perrigault et al. (2012). They created a one-dimensional heat transfer (radiative, convective, and conductive) model that included the following parameters: the geometry of the modelled object, solar radiation, ambient temperature, and wind velocity, while the results of the calculations were the temperature of slurry, biogas, walls, cover, holding membrane, and the greenhouse air. The correctness of the model was verified positively by comparison with the measurement results. According to the authors, their model may be useful in predicting the influence of the geometry and materials on the thermal performance of the anaerobic digester.

Biogas plants have enjoyed great popularity in China. In 2010, there were over 30000 average-sized and large installations. A typical stirred bioreactor treating pig manure was tested by Guo et al. (2013). The optimum fermentation temperature and organic loading rates were the main parameters that could be determined using a mathematical model created by the above-mentioned team of scientists. The results obtained from the calculations agreed with the experimental data for an ambient temperature only greater than $20^{\circ} \mathrm{C}$. The authors suggested that the maximum energy production can be achieved when the digesters run at organic dry matter of $4.6-5.4 \mathrm{~kg} / \mathrm{m}^{3}$ and the temperature of mesophilic fermentation is around $26^{\circ} \mathrm{C}$ for an external temperature around $10-20^{\circ} \mathrm{C}$.

Shaheen and Nene (2014) carried out an analysis of the heat transfer from the slurry and the gas dome to the external environment. The biogas plant was located at the Maharashtra Institute of Technology (India). The model of this object was created using Matlab software. The results of the thermal simulations can be used for optimal control of the biogas plant operation.
The energy simulation of an anaerobic digester buried in the ground was done by Terradas-III et al. (2014) in order to obtain the production of biogas. A one-dimensional heat transfer model was applied to obtain the slurry and biogas temperature. As shown by the results of the calculations, the proposed model allowed accurate prediction of the amount of biogas production and the temperature inside the digester chamber.

Hreiz et al. (2017) developed a computer tool that can be useful for engineers in the design of semi-buried anaerobic digesters. The model proposed by the authors was based on the heat transfer balance and allowed calculation of the temperature in the fermenter as a function of the following parameters: ambient temperature, solar irradiation, wind speed, and intensity of rainfall. As it turned out, the results of the operating temperature simulations were in good agreement with the experimental measurements. A significant achievement of this work was showing the major sources of heat losses from the digester chamber.

As it turned out, there is no information on the heat balance of biogas plants under the Polish climatic conditions in the literature. In most cases, such investments implemented in Poland are based on ready-made projects of biogas plants drawn up for conditions prevailing in Germany. Therefore, the authors of the current paper decided to pursue this subject, i.e. the estimation of the heat losses of the digester under the Polish climate conditions.

\section{DESCRIPTION OF THE RESEARCH OBJECT UNDER INVESTIGATION}

The biogas plant subjected to analysis, shown in Figure 1a, is located near the village of Ryboly (Poland). The research object consists of two cylinder-shaped anaerobic digesters. They have the same dimensions, i.e. diameter of $30 \mathrm{~m}$ and height of $6 \mathrm{~m}$. The fermentation chambers are buried $1 \mathrm{~m}$ into the ground. The cylindrical outer wall and the bottom are made of $25 \mathrm{~cm}$-thick reinforced concrete. They were insulated using extruded polystyrene with a thickness of $10 \mathrm{~cm}$. The chambers are covered with a flexible dome in a shape similar to a cone. The four heating loops connected in parallel, made of steel pipes with a diameter of $60 \mathrm{~mm}$, are attached to the walls of the tank in its lower part. Due to the fact that both 
a)

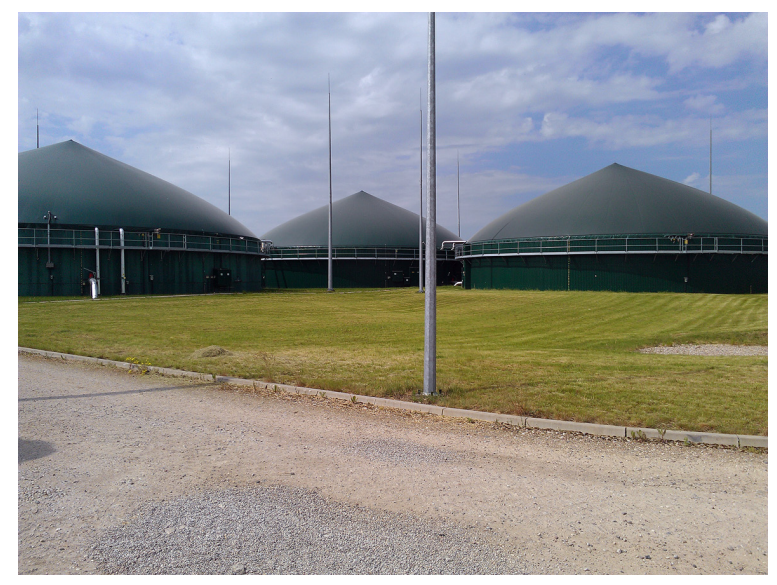

b)

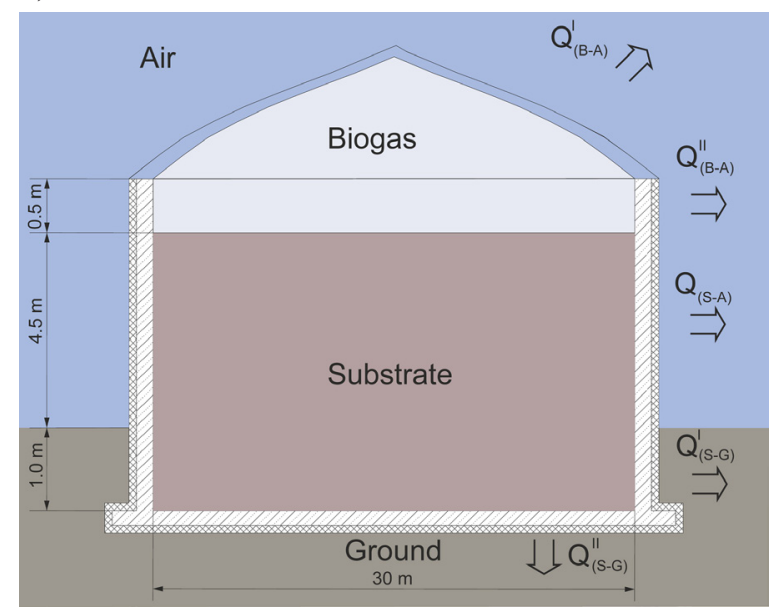

Figure 1. Ryboly Biogas Plant: a) fermentation chambers and the storage tank, b) physical model of biogas digester (not to scale)

fermentation chambers have identical dimensions, further computational analysis was carried out for a single digester.

\section{ANALYSIS OF HEAT LOSS FROM A BIOGAS ANAEROBIC DIGESTER}

The computational analysis presented in this article considers the anaerobic digester shown in Figure $1 \mathrm{~b}$. The total heat losses $Q_{T}$ through the digester presents the following sum of the partial heat losses (Fig. 1b):

$$
\begin{aligned}
Q_{T} & =Q_{(B-A)}^{I}+Q_{(B-A)}^{I I}+Q_{(S-A)}+ \\
& +Q_{(S-G)}^{I}+Q_{(S-G)}^{I I},[\mathrm{~W}]
\end{aligned}
$$

where: $Q_{(B-A)}^{I}$ are the heat losses due to heat transfer through the pneumatic cover of the reactor (gas products - air),

$Q_{(B-A)}^{I I}$ are the heat losses due to heat transfer through the vertical wall (gas products - air),

$Q_{(S-A)}$ are the heat losses due to heat transfer through the vertical wall (substrate - air),

$Q_{(S-G)}^{I}$ are the heat losses due to heat transfer through the vertical wall (substrate - ground)

$Q_{(S-G)}^{I I}$ are the heat losses due to heat transfer through the bottom of the tank (substrate - ground).

The fermentation chamber has the shape of a cylinder (inner diameter of $30 \mathrm{~m}$ ) with a coneshaped cover with an angle of inclination forming a cone to the base plane of 30 degrees. In many practical cases, when the thickness of the cylindrical wall is small compared to the diameter, the equations relating to heat transfer through flat walls can be used for thermal calculations. The heat losses through the reactor flat walls are determined according to the following relationship:

$$
Q_{n}=U \cdot A_{n} \cdot\left(T_{i}-T_{e}\right),[\mathrm{W}]
$$

where: $U$ is the heat transfer coefficient $[\mathrm{W} /$ $\left.\left(\mathrm{m}^{2} \mathrm{~K}\right)\right]$,

$A$ is the area of the partition $\left[\mathrm{m}^{2}\right]$,

$T_{i}$ is the temperature in the fermentation chamber

$T_{e}$ is the ambient temperature.

Figure 2 presents the distribution of average monthly temperature inside the fermentation chamber $T_{i}$ and the average monthly external temperature $T_{e}$ measured in 2016. Inside the fermentation chamber, the average annual temperature $T_{i}=40^{\circ} \mathrm{C} \pm 0.5^{\circ} \mathrm{C}$ was assumed. Under the foundation slab, a constant temperature of $8^{\circ} \mathrm{C}$ was adopted, while for the walls in contact with the ground, the average temperature was determined according to the dependence presented in the literature (Biernacka, 2010).

In order to determine the heat transfer coefficient of the biogas walls, the PN-EN ISO 6946 standard was used:

$$
U=\frac{1}{R_{s i}+\sum_{i=1}^{n} \frac{d_{i}}{k_{i}}+R_{s e}},\left[\frac{\mathrm{W}}{\mathrm{m}^{2} \mathrm{~K}}\right]
$$

where: $k$ is the thermal conductivity coefficient, 
$d_{i}$ is the thickness of the material layer in the component,

$R_{s i}$ and $R_{s e}$ are the resistances of heat transfer on the inner and outer surface of the walls of the digester, respectively.

These values were assumed in accordance with the EN ISO 6946 (2017) standard. The convective heat transfer coefficient from the substrate was determined based on Dewil et al. (2007) and was equal $500 \mathrm{~W} /\left(\mathrm{m}^{2} \mathrm{~K}\right)$. The fermentation chamber is covered with a polymer mesh and a pneumatic roof made of EPDM rubber. Tab. 1 presents the results obtained from the calculations of the heat transfer coefficient from the formula (3) for the partitions of the digester. The highest heat transfer coefficient is for the covering of the fermentation chamber, while the smallest value is for the foundation plate.

In order to simulate the heat losses in the digester for various climate zones, a computer program was written in the Fortran language, in which formulas (1-3) were used. The simulations of heat transfer through the components of the digester were made for the outdoor temperatures from $-25^{\circ} \mathrm{C}$ to $20^{\circ} \mathrm{C}$. Figure 3

Table 1. Heat transfer coefficients for the partitions of the digester

\begin{tabular}{|l|c|}
\hline \multicolumn{1}{|c|}{ Description } & $\mathrm{U}\left(\mathrm{W} / \mathrm{m}^{2} \mathrm{~K}\right)$ \\
\hline $\begin{array}{l}\text { Covering of the anaerobic digester (gas } \\
\text { products - air) }\end{array}$ & 2.08 \\
\hline Wall (gas products - air) & 0.32 \\
\hline Wall (substrate - air) & 0.34 \\
\hline Wall (substrate - ground) & 0.30 \\
\hline Foundation plate (substrate - ground) & 0.15 \\
\hline
\end{tabular}

presents the results of calculations of the heat loss through the partitions of the digester, depending on the outside temperature, assuming a constant temperature of the substrate inside the reactor. The temperature inside the biogas plant, determined by its designer $\left(T_{i}=40^{\circ} \mathrm{C}\right)$, was set in the calculations. In the case of insufficient thermal insulation of the fermentation chamber, this temperature may change (Fig. 2). With the decrease of the outside temperature, the heat losses through the walls of the digester increase. However, the greatest increase in heat losses takes place through walls in contact with the external air. In the winter period, the impact of the heat loss on the temperature inside the fermentation chamber is visible by lowering its value below $40^{\circ} \mathrm{C}$ (Fig. 2), which also affects the efficiency of the digester.

In order to estimate the accuracy of determination of heat losses through the digester, the surface temperature of the walls (substrate - air) and covers of the digester (gas products - air) estimated from the calculations were compared to the average temperature measured with a thermal imaging camera. The average temperature of the selected surfaces was obtained from the thermal image according to the following relationship:

$$
T_{m}=\frac{1}{A} \iint_{A} T d A,\left[{ }^{o} C\right]
$$

where: $A$ is the surface area of the wall.

As it turned out, the maximum relative differences in the average temperature was less than $9.5 \%$, which proves the high accuracy of computer simulations.

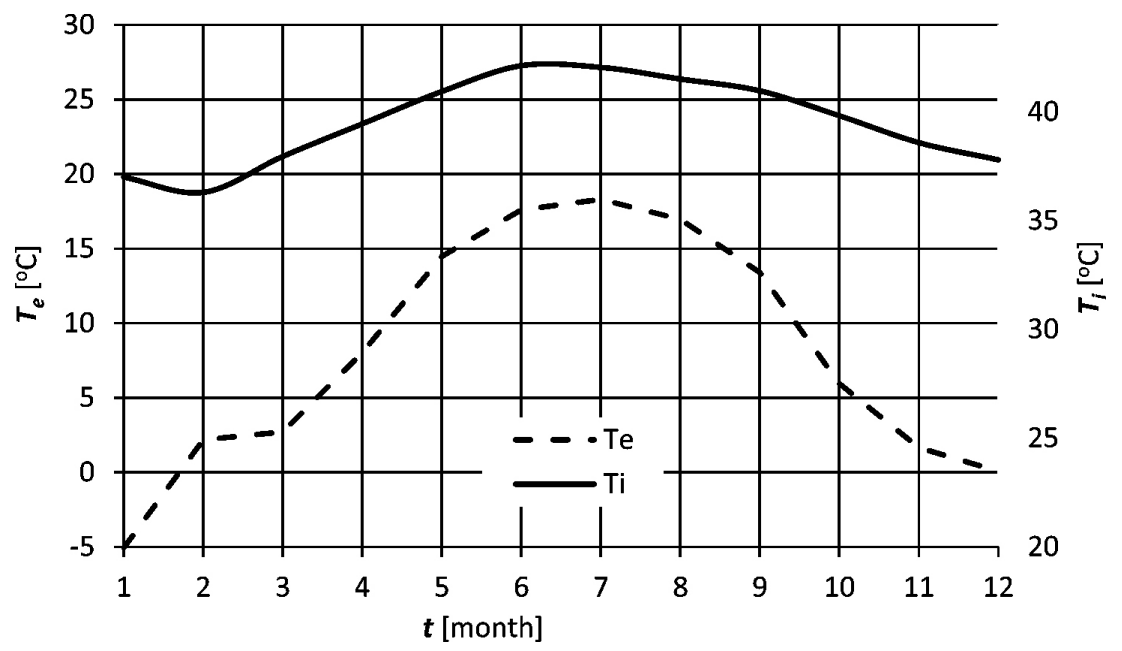

Figure 2. Average monthly temperature $T_{i}$ and $T_{e}$ measured in 2016 


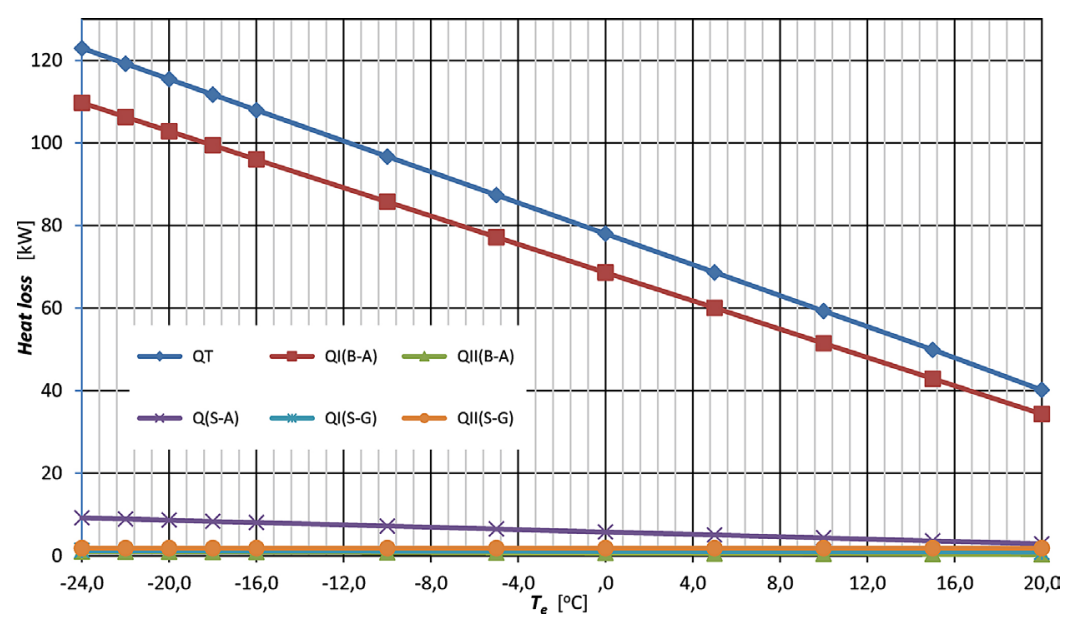

Figure 3. Computational heat losses through the walls of the digester depending on the outside temperature

\section{RESULTS AND DISCUSSION}

The basic parameter necessary to determine the heat loss is the design external temperature. The influence of the external temperature in various geographic locations on the operation of biogas plants is described extensively in the literature (El-Mashad et al. 2006, Gebremedhin et al. 2005, Wu and Bibeau 2006, Merlin et al. 2012). Marlin et al. (2012) determined the temperature in the unheated digester versus various ambient air and wastewater temperatures.

The design external temperature for Poland is found in the PN-EN-12831 (2017) standard. According to this standard, Poland is divided into five climatic zones, where the outdoor temperatures are: $-16^{\circ} \mathrm{C},-18^{\circ} \mathrm{C},-20^{\circ} \mathrm{C},-22^{\circ} \mathrm{C},-24^{\circ} \mathrm{C}$ for zones I, II, III, IV, V, respectively. The heat losses determined on the basis of the design external temperature for the presented biogas plant are shown in Figure 4. The largest total heat losses are generated by the biogas plants in the fifth climatic zone, and these losses are higher by $13.88 \%, 10.06 \%, 6.49 \%, 3.14 \%$ for I, II, III, and IV zones, respectively.

Figure 5 shows the percentage share of heat losses through building partitions in relation to the total heat losses of the digester in the fourth climatic zone. The largest heat losses are through the covering of the digester, which amounts to as much as $90 \%$ of the total heat loss. The smallest heat losses occur through the walls and the foundation slab. It should be noted that this condition may be influenced by the depression in the ground of the digester and the shape of the fermentation chamber. Gebremedhin et al. (2005) described the effect of these two parameters on the heat loss of the digester. According to this study, the heat loss by a covering the cylindrical digester at a depth of $1 \mathrm{~m}$ in the ground

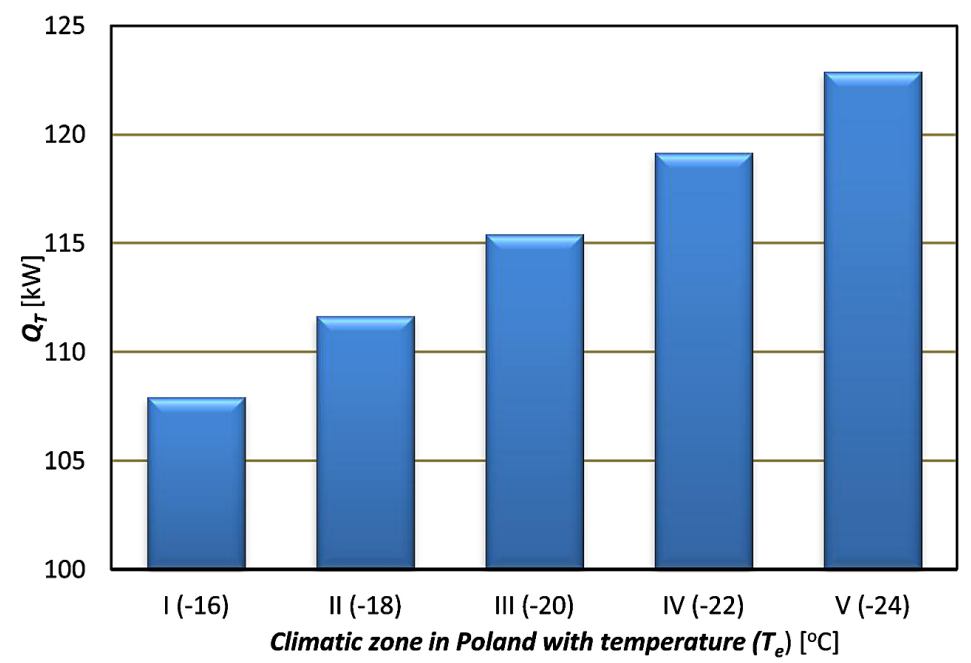

Figure 4. Total heat losses from the one digester chamber in five climatic zones in Poland 


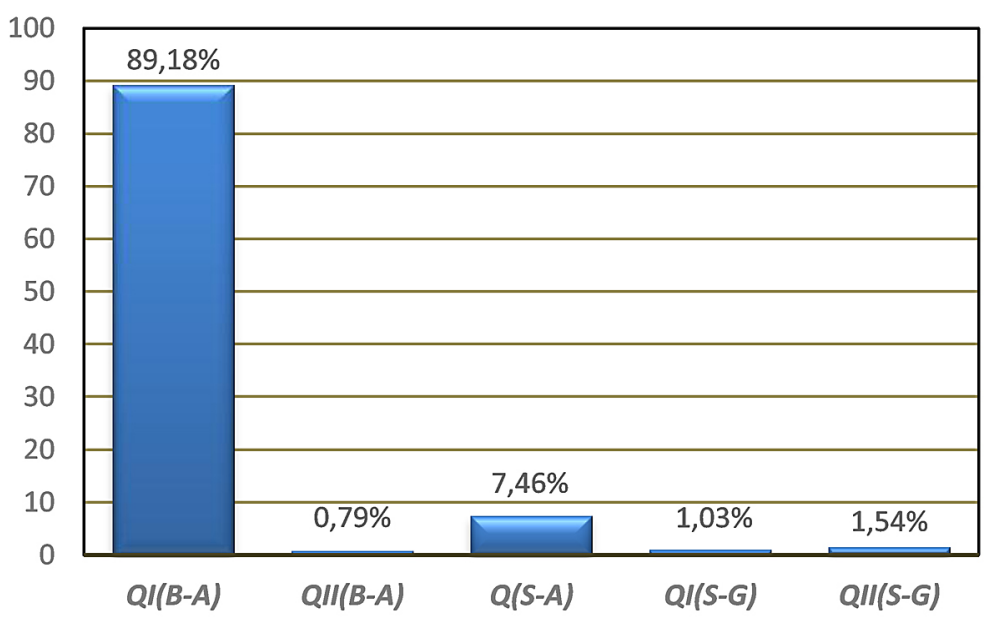

Figure 5. Share of heat losses through partitions in relation to the total heat loss of the digester

a)

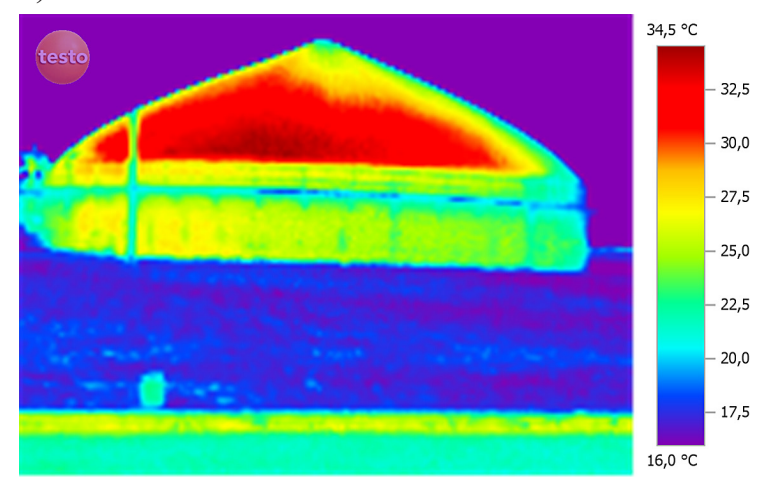

b)

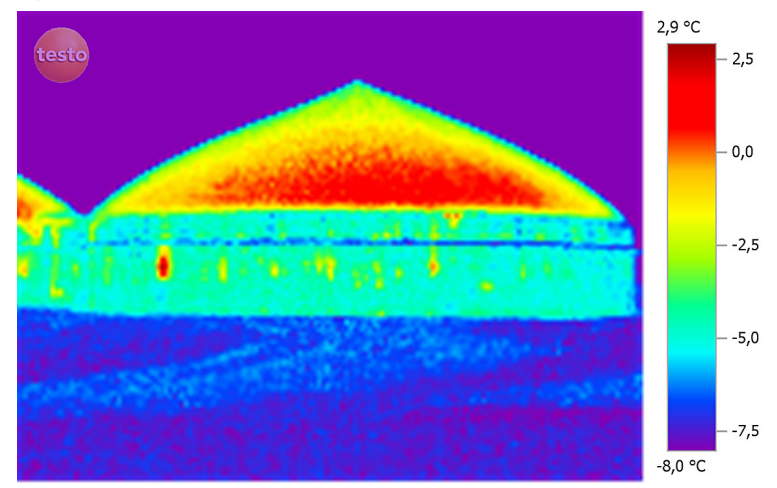

Figure 6. Thermal image of the digester in two different seasons: a) summer period $\left.\left(T_{e}=20^{\circ} \mathrm{C}\right), \mathrm{b}\right)$ winter period $\left(T_{e}^{\left.=-6^{\circ} \mathrm{C}\right)}\right.$

is about $74 \%$ of total heat losses. Gebremedhin et al. (2005) shows that the cylindrical digester with a flat top represents the best geometry for minimizing heat loss. In the presented work, the covering of the fermentation chamber is made in the shape of a cone, which additionally increases the heat loss. Figure 6 shows a view of two thermal images of the fermentation chamber in two different seasons: in summer, where the outside temperature was $20^{\circ} \mathrm{C}$ (Fig. 7a), and in winter, where the outside temperature was $-6^{\circ} \mathrm{C}$ (Fig. 7b). These two thermal images were taken on a cloudy day. In both cases, i.e. in summer and winter, the highest temperature can be found on the cover of the digester. It should be noted that the presented work does not include the heat gains from beam solar radiation. On a cloudy day, only a diffuse radiation occurs.

Figure 7 presents the dependence of the energy measured in 2016 necessary for heating fermentation chambers depending on the month. The highest consumption of energy was in autumn and winter, while the lowest was in the summer. For example, in December 2016, the energy consumption for heating digesters was up to eight times higher than in July 2016. A similar work trend of the heat exchanger was calculated by Hreiz et al. (2017) for a semi-buried agricultural anaerobic digester located in north-eastern France, near the city of Nancy in the Lorraine region.

Thermal bridges also cause a certain amount of heat loss. The main reason for the occurrence of thermal bridges involves the design or assembly errors. The most common thermal bridges are caused by: breaking the continuity of the insulation layer, insufficient thickness of the thermal insulation layer and inhomogeneity of the partition structure, i.e. occurrence of elements that conduct heat better in the construction of the partition. Figure 8 shows an example of a linear thermal bridge, which is caused by too thin a layer of insulation between the wall of the digester and the ground. Figure 9 shows the thermal bridge of a manifolds box of the heating chamber distributor. The next figure (Fig. 10) shows the thermal bridge of a poorly insulated pipe supplying the 


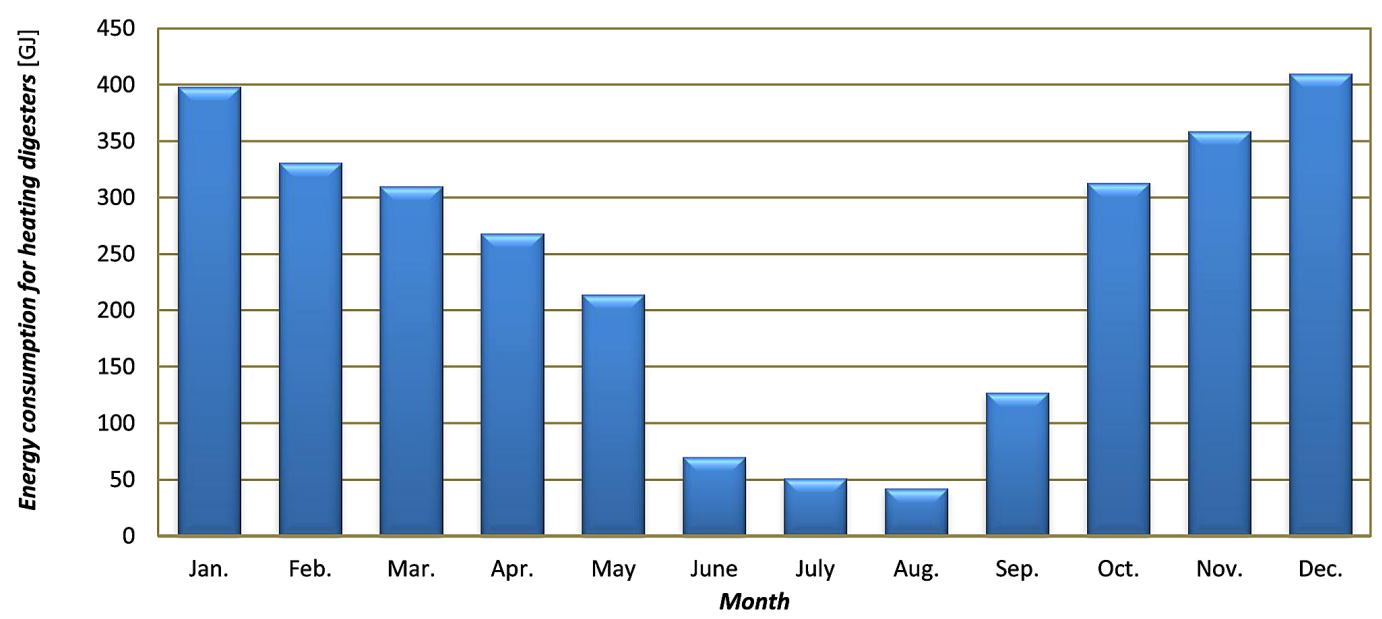

Figure 7. Energy consumption for heating of one digester measured in 2016

a)

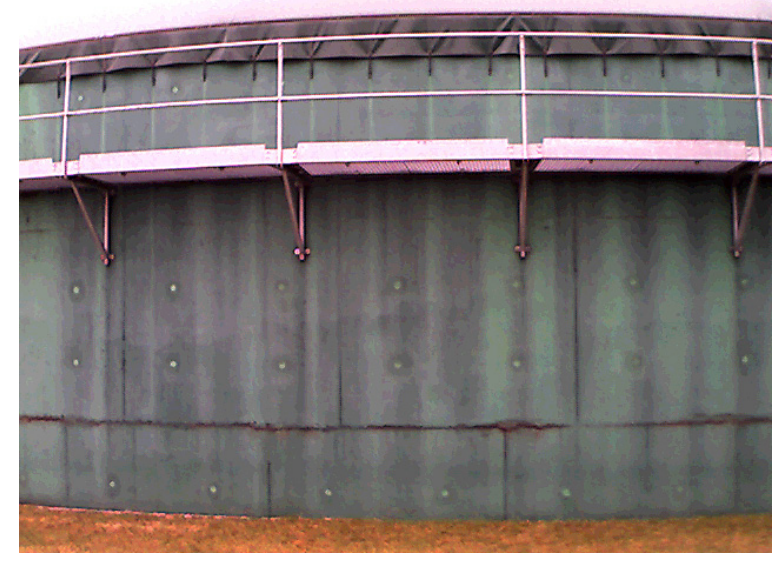

b)

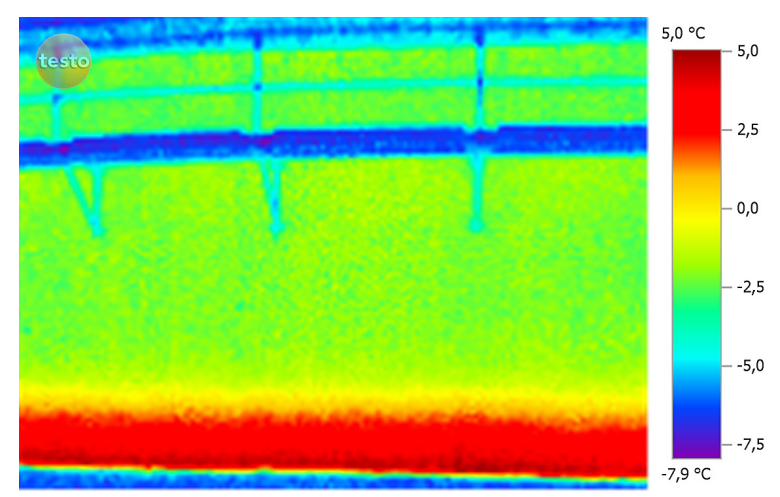

Figure 8. An example of a linear thermal bridge of the vertical wall of the digester:

a) view of the wall $b$ ) thermal image

a)

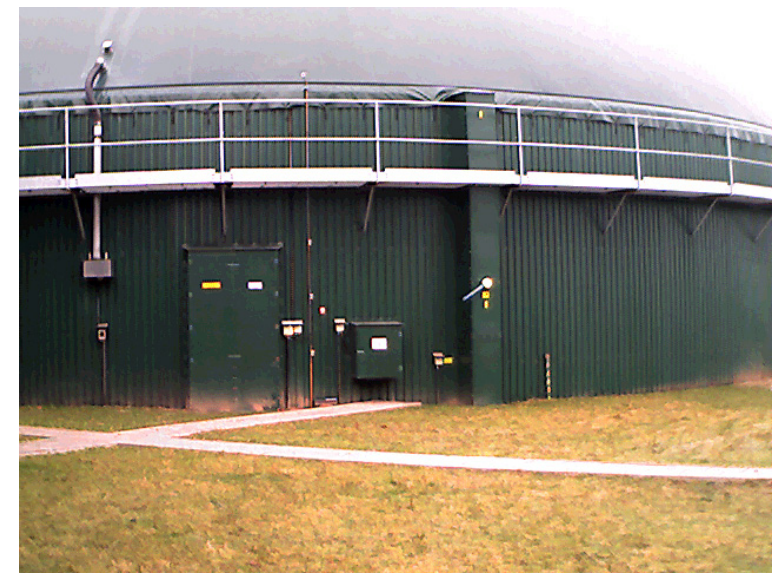

b)

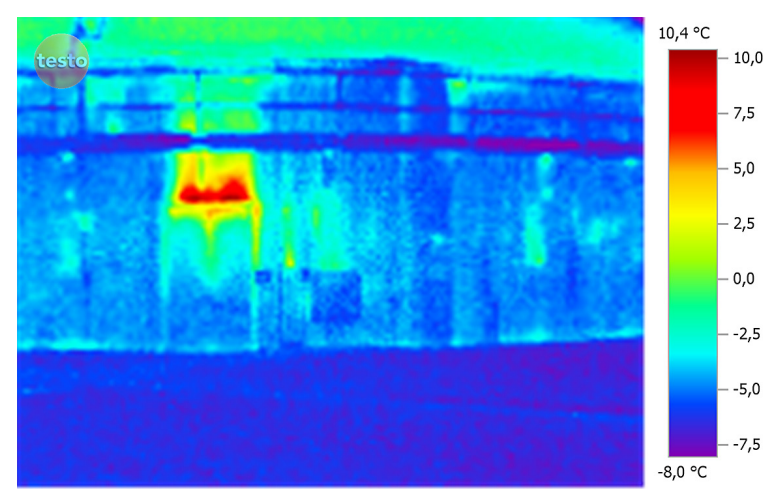

Figure 9. An example of a thermal bridge located in the heat distributor box on the wall of the fermenting chamber: a) general view, b) thermal image 
a)

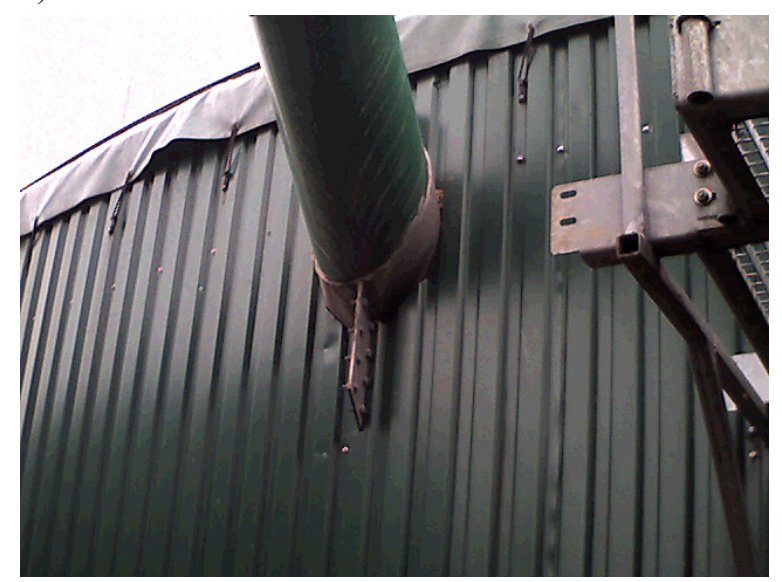

b)

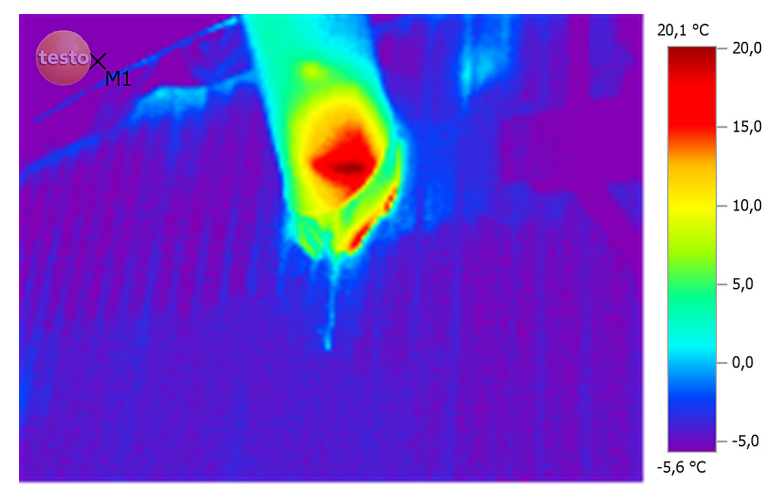

Figure 10. An example of a thermal bridge caused by the lack of proper insulation of the pipe supplying the substrate to the digester: a) general view, b) thermal image

a)

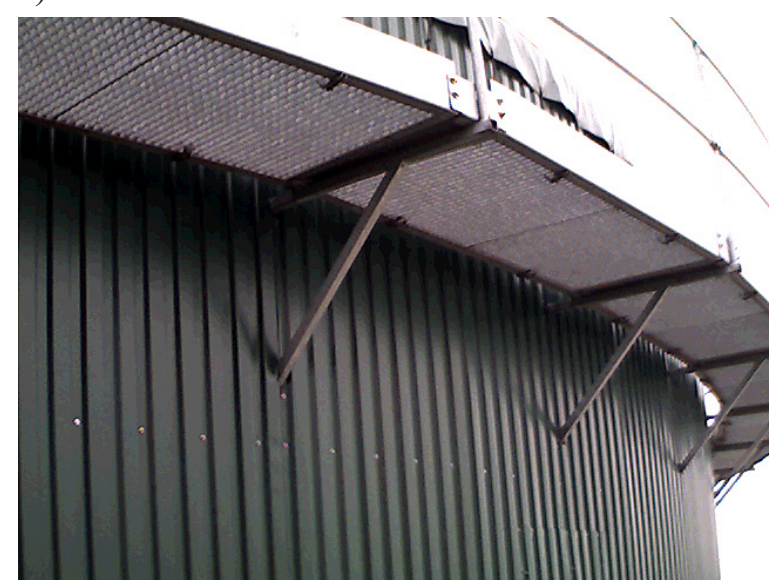

b)

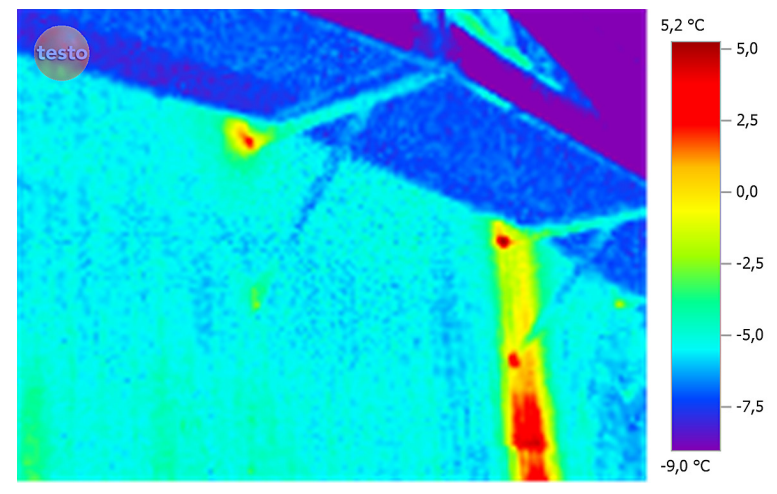

Figure 11. An example of point thermal bridges caused by the use of thermally non-insulated pins for attaching the platform to the wall of the digester: a) general view b) thermal image

substrate to the digester. On the other hand, Figure 11 shows the point thermal bridges caused by incorrect pins connecting the platform with the wall of the fermentation chamber.

\section{CONCLUSION}

The paper presents a heat loss analysis for a typical biogas plant under the Polish climatic conditions. The simulations were made for an existing object. It should be noted that properly made thermal insulation of the biogas plant contributes to the stabilization of the temperature inside the fermentation chamber, and especially prevents the temperature drops inside the digester in winter. On the basis of the conducted research, the following conclusions were drawn:

1. Heat losses through the cover account for about $90 \%$ of the digester heat losses. In order to reduce this effect, the authors propose additional insulation of the cover or heating of the air space in the cover with warm air in the winter. The heating of the fermentation chamber cover can be made using the waste heat from a biogas plant.

2. The smallest heat losses occur at the interface between the walls of the digester and the soil. Therefore, in order to improve the energy balance, maximum thermal insulation foundation of the digester in the ground is recommended.

3. In this work, thermal bridges were not assumed in the calculations. However, it should be remembered that bridges can have a relatively high impact on the energy losses from the digester. Many thermal bridges were detected using a thermal imaging camera. In order to reduce the heat loss, it is recommended to eliminate thermal bridges both at the design stage and at the construction of the digester. 


\section{Acknowledgments}

This work was performed within the framework of Grant No. S/WBIIS/4/2014 of Bialystok University of Technology and financed by the Ministry of Science and Higher Education of the Republic of Poland.

\section{REFERENCES}

1. Białowiec A., Wiśniewski D., Pulka J., Siudak M., Jakubowski B., Myślak B. 2015. Biodrying of the Digestate from Agricultural Biogas Plants. Annual Set The Environment Protection, 17(2), 1554-1568 (in Polish).

2. Biernacka B. 2010. Semi-empirical formula for the natural ground temperature distribution in Bialystok city region. Civil and Environmental Engineering, 1, 5-9 (in Polish).

3. Dewil R., Appels L., Baeyens J. 2007. Improving the heat transfer properties of waste activated sludge by advanced oxidation processes. Proceedings of European Congress of Chemical Engineering (ECCE-6) Copenhagen, 16-20 September 2007.

4. El-Mashad H.M., Van Loon W.K., Zeeman G., Bot G.P., Lettinga G. 2004. Design of a solar thermophilic anaerobic reactor for small farms. Biosyst. Eng., 87 (3), 345-353.

5. EN ISO 6946:2017-10 Building components and building elements - Thermal resistance and thermal transmittance - Calculation method.

6. Gebremedhin K.G., Wu B., Gooch C., Wright P., Inglis S. 2005. Heat transfer model for plug-flow anaerobic digesters. Trans. ASAE, 48 (2), 777-785.

7. Guo J., Dong R., Clemens J., Wang W. 2013. Thermal modelling of the completely stirred anaerobic reactor treating pig manure at low range of mesophilic conditions. Journal of Environmental Management, 127, 18-22.

8. Hreiz R., Adouani N., Jannot Y., Pons M.-N. 2017. Modeling and simulation of heat transfer phenomena in a semi-buried anaerobic digester. Chemical Engineering Research and Design, 119, 101-116.
9. Kogut P., Piekarski J., Dąbrowski T., Kaczmarek F. 2012. Biogas production plants as a method of utilisation of sewage sludge in relation to the polish legislation. Annual Set The Environment Protection, 14, 299-313 (in Polish).

10. Lebiocka M., Montusiewicz A., Zdeb M. 2010. Anaerobic co-digestion of sewage sludge and old landfill leachate. Polish Journal of Environmental Studies, Series of Monographs, 2, 141-145.

11. Merlin G., Kohler F., Bouvier M., Lissolo T., Boileau H. 2012. Importance of heat transfer in an anaerobic digestion plant in a continental climate context. Bioresour. Technol. ,124, 59-67.

12. Montusiewicz A. 2014. Co-digestion of sewage sludge and mature landfill leachate in pre-bioaugmented system. Journal of Ecological Engineering, 15(4), 98-104.

13. Perrigault T., Weatherford V., Martí-Herrero J., Poggio D. 2012. Towards thermal design optimization of tubular digesters in cold climates: A heat transfer model. Bioresource Technology, 124, 259-268.

14. Pilarska A. A. 2018. Anaerobic co-digestion of waste wafers from confectionery production with sewage sludge. Polish Journal of Environmental Studies, 27(1), 237-245.

15. PN-EN 12831-1:2017-08 Heating systems in buildings - Method for calculation of the design heat load.

16. Sadecka Z., Suchowska-Kisielewicz M. 2016. Cofermentation of Chicken Manure. Annual Set The Environment Protection, 18, 609-625 (in Polish).

17. Shaheen M., Nene A. A. 2014. Thermal simulation of biogas plants using Matlab. International Journal of Engineering Research and Applications, 4, 24-28.

18. Terradas-III G., Triolo J. M., Pham C. H., MartíHerrero J., Sommer S. G. 2014. Thermic model to predict biogas production in unheated fixed dome digesters buried in the ground. Environmental Science and Technology, 48, 3253-3262.

19. Wu B., Bibeau E.L. 2006. Development of 3-D anaerobic digester heat transfer model for cold weather applications. Trans. Am.Soc. Agric. Eng., 49 (3), 7749-7757. 